\title{
6-shogaol treatment improves experimental knee OA exerting a pleiotropic effect over immune innate signaling response in chondrocytes
}

\author{
Paula Gratal ${ }^{1}$, Aranzazu Mediero ${ }^{1}$, Ana Lamuedra ${ }^{1}$, Alejandra Matamoros-Recio ${ }^{2}$, Gabriel \\ Herrero-Beaumont $^{1}$, Sonsoles Martín-Santamaría ${ }^{2}$, and Raquel Largo ${ }^{1}$ \\ ${ }^{1}$ Instituto de Investigacion Sanitaria de la Fundacion Jimenez Diaz \\ ${ }^{2}$ Centro de Investigaciones Biológicas Margarita Salas, CIB-CSIC
}

August 20, 2021

\begin{abstract}
Background:The pathogenesis of osteoarthritis (OA) implicates a low-grade inflammation associated to the activation of the innate immune system. Toll like receptor (TLR) stimulation triggers the release of inflammatory mediators, which aggravate OA severity. The aim was to study the preventive effect of 6-shogaol (6S), a potential TLR4 inhibitor, on the treatment of experimental knee OA. Experimentalapproach:OA was induced in C57BL6 mice by surgical section of the medial meniscotibial ligament, which received $6 \mathrm{~S}$ for eight weeks. Cartilage damage, inflammatory mediator presence, and disease markers were assessed in the joint tissues by immunohistochemistry. Computational modeling was used to predict binding modes of $6 \mathrm{~S}$ into the TLR4/MD2 receptor and its permeability across cellular membranes. Employing LPS-stimulated chondrocytes and MAPK assay we clarified $6 \mathrm{~S}$ action mechanisms. Results: $6 \mathrm{~S}$ treatment was able to prevent articular cartilage lesions, synovitis, and the presence of pro-inflammatory mediators and disease markers in OA animals. Molecular modeling studies predicted 6S interaction with the TLR4/MD-2 heterodimer in an antagonist conformation through its binding into the MD-2 pocket. In cell culture, we confirmed that $6 \mathrm{~S}$ reduced LPS-induced TLR4 inflammatory signaling pathways. Besides, MAPK assay demonstrated that 6S directly inhibits the ERK1/2 phosphorylation activity. Conclusion:6S evoked a preventive action on cartilage and synovial inflammation in $\mathrm{OA}$ mice. $6 \mathrm{~S}$ effect may take place not only by hindering the interaction between TLR4 ligands and the TLR4/MD-2 complex in chondrocytes, but also through inhibition of ERK phosphorylation, implying a pleiotropic effect on different mediators activated during OA, which proposes it as an attractive drug for OA treatment.
\end{abstract}

\section{Hosted file}

Manuscript BJP 202107 20.pdf available at https://authorea.com/users/431175/articles/5347016-shogaol-treatment-improves-experimental-knee-oa-exerting-a-pleiotropic-effect-overimmune-innate-signaling-response-in-chondrocytes 


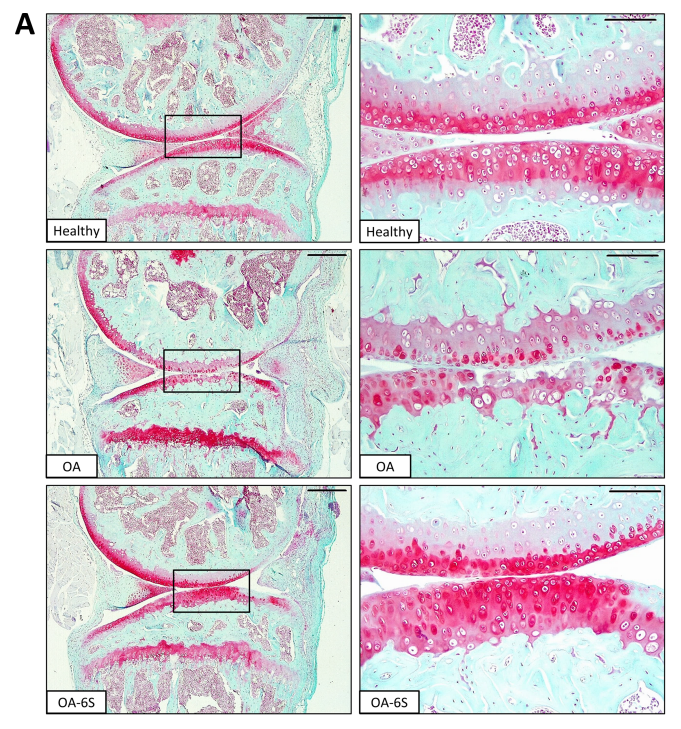

B
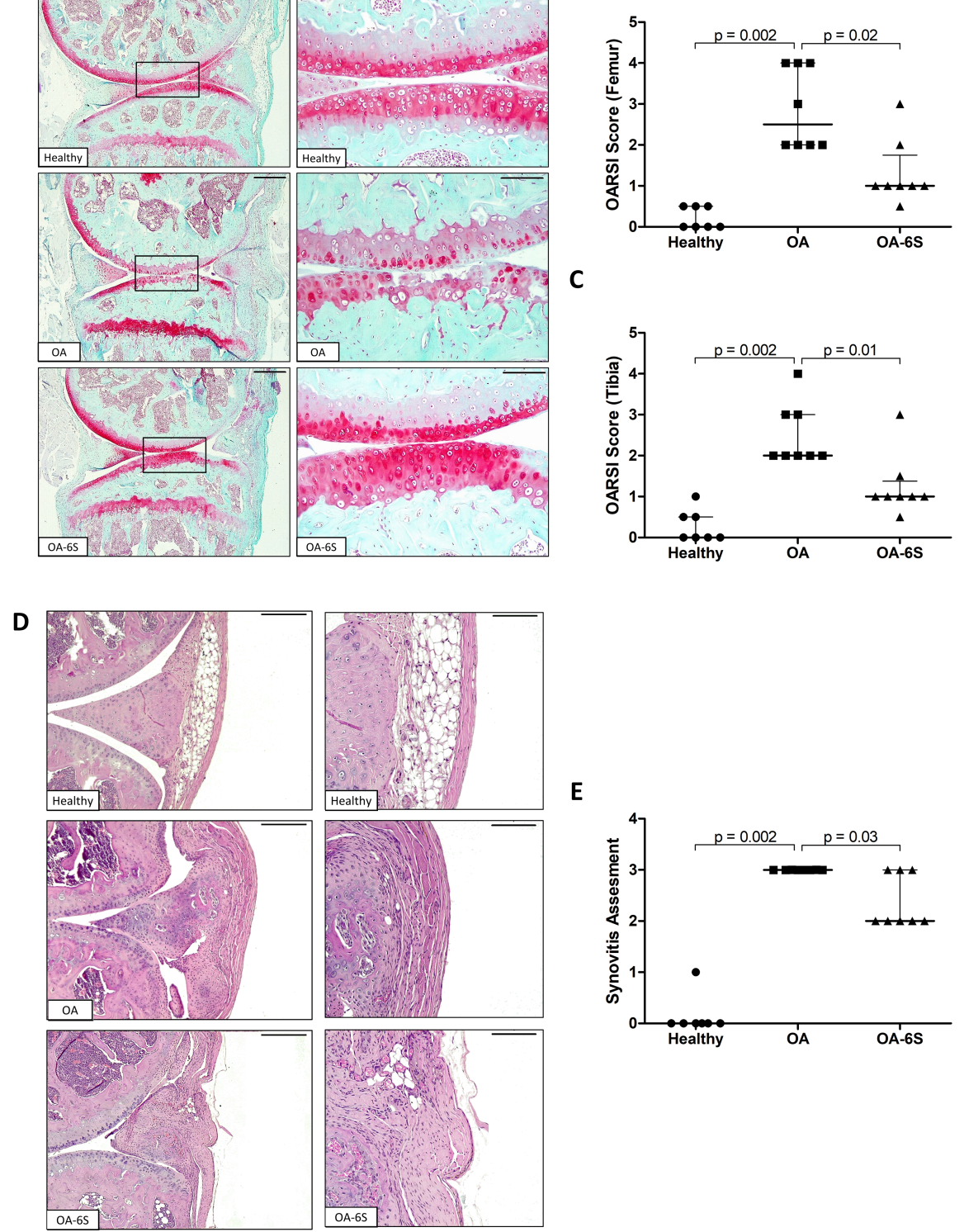

\section{E}
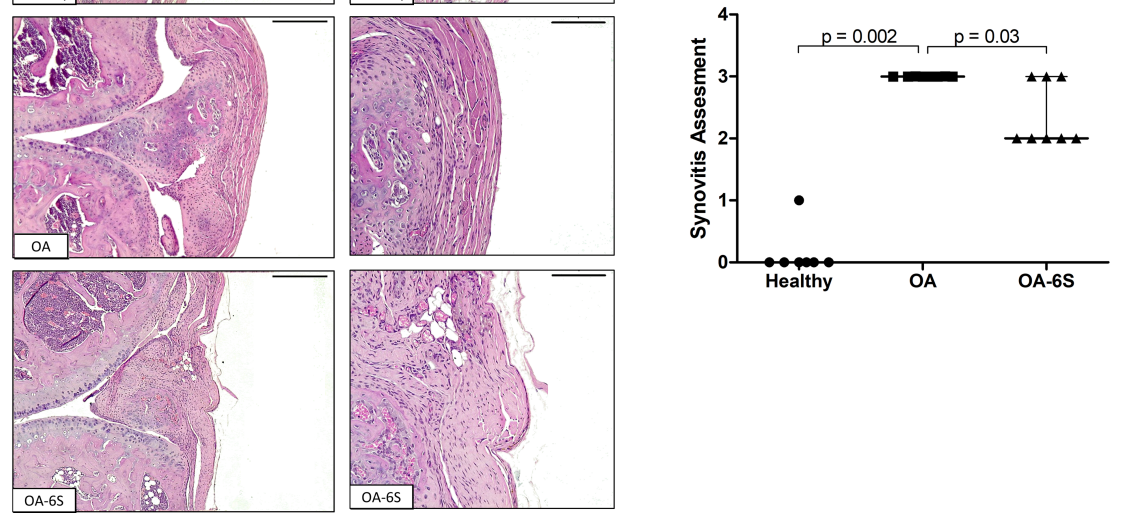
A

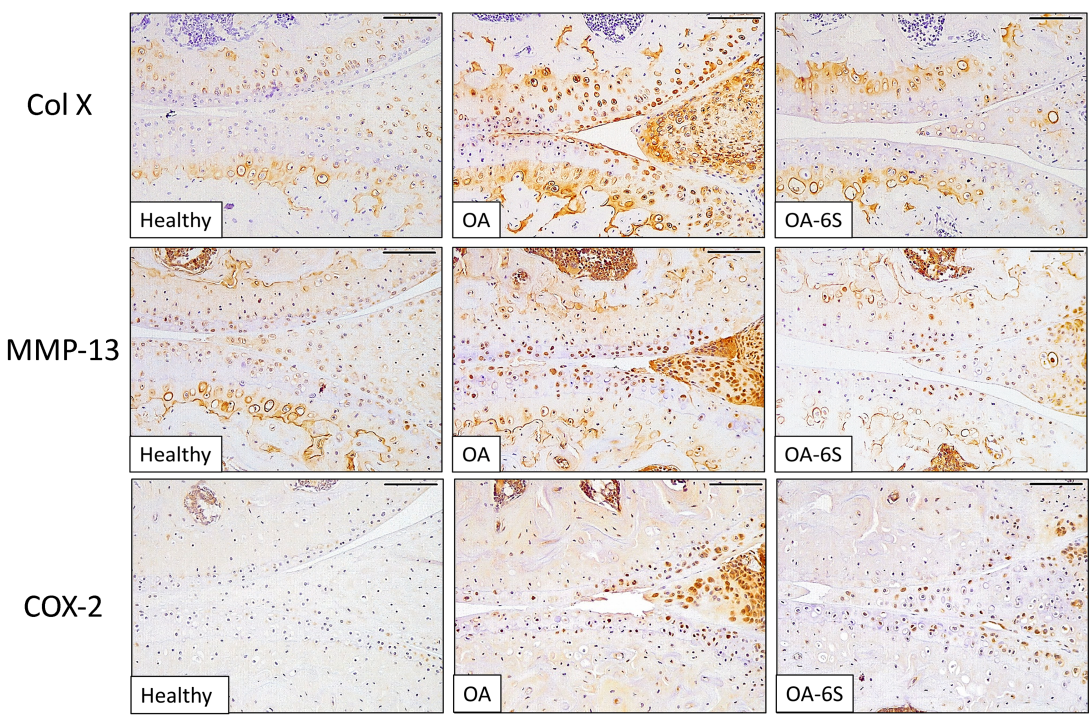

B

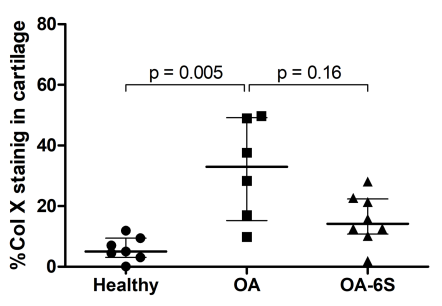

D

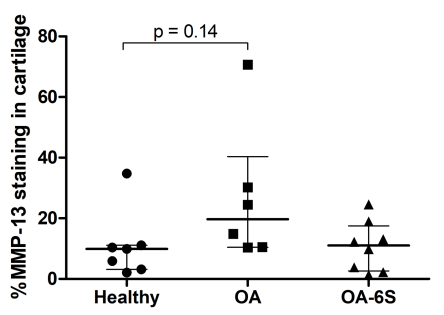

F

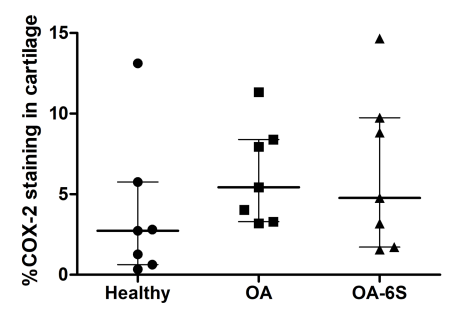

H

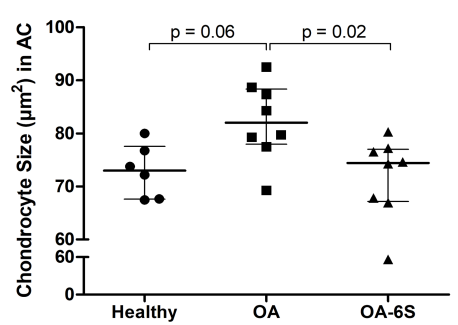

C

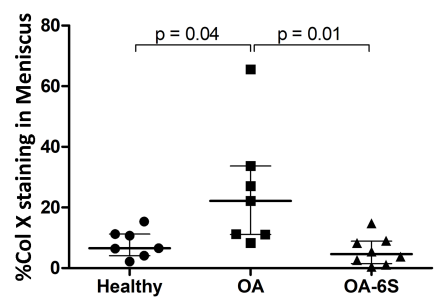

E

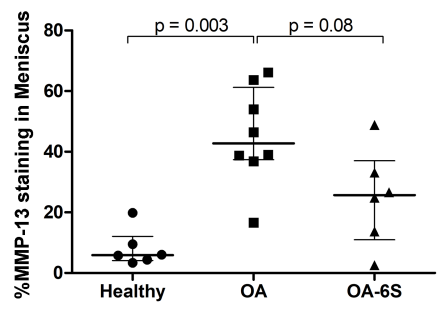

G

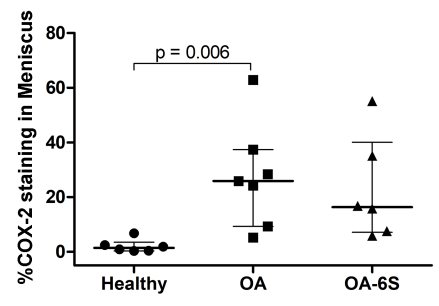

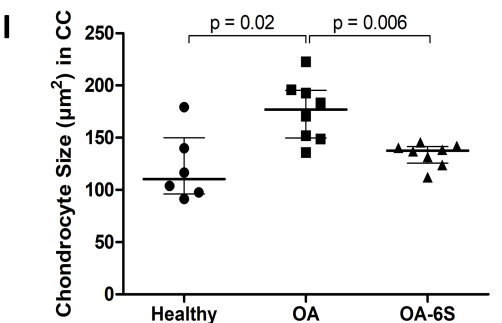


A

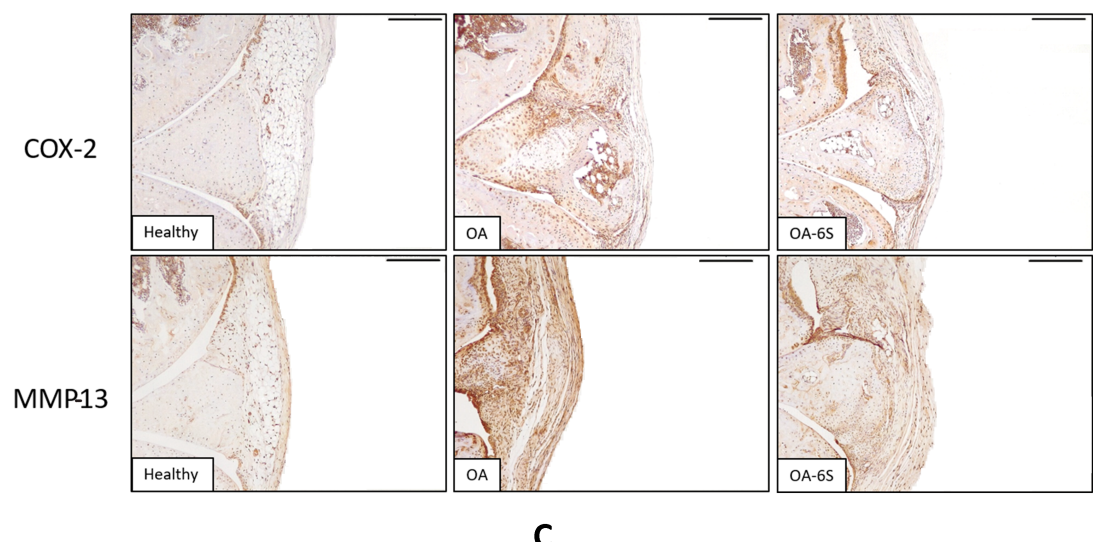

B

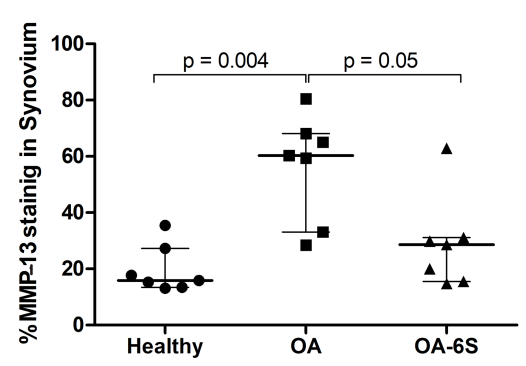


A

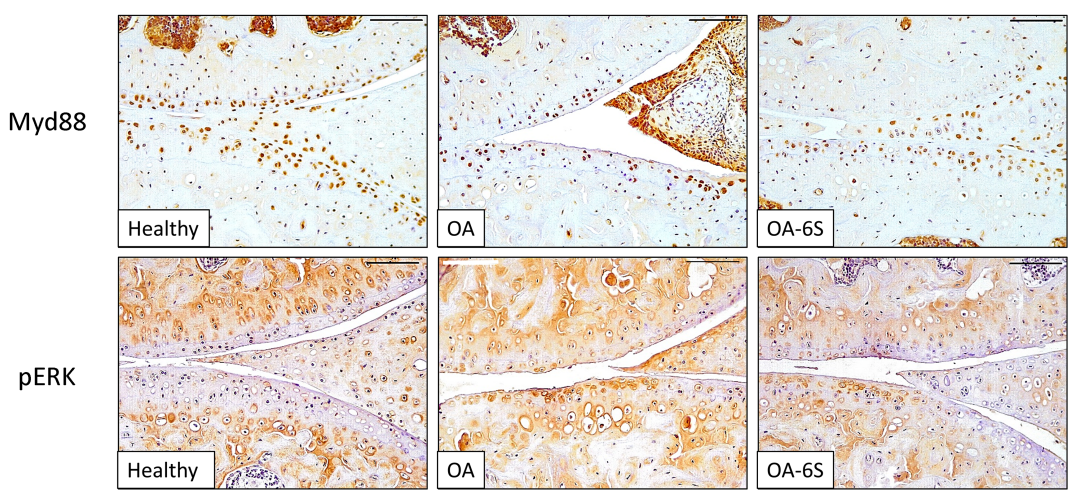

B

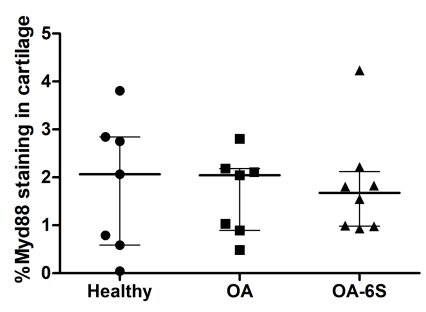

D

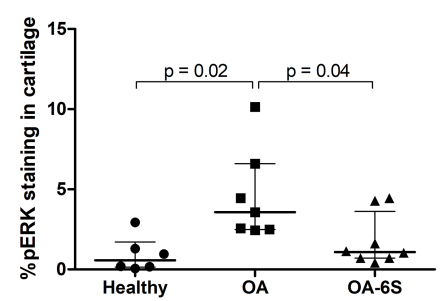

C

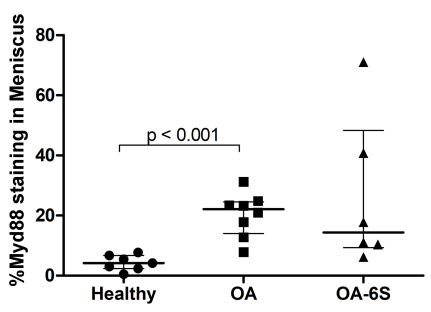

E

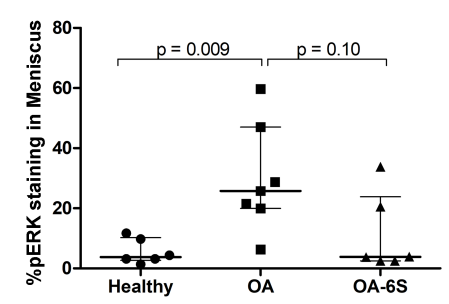

F

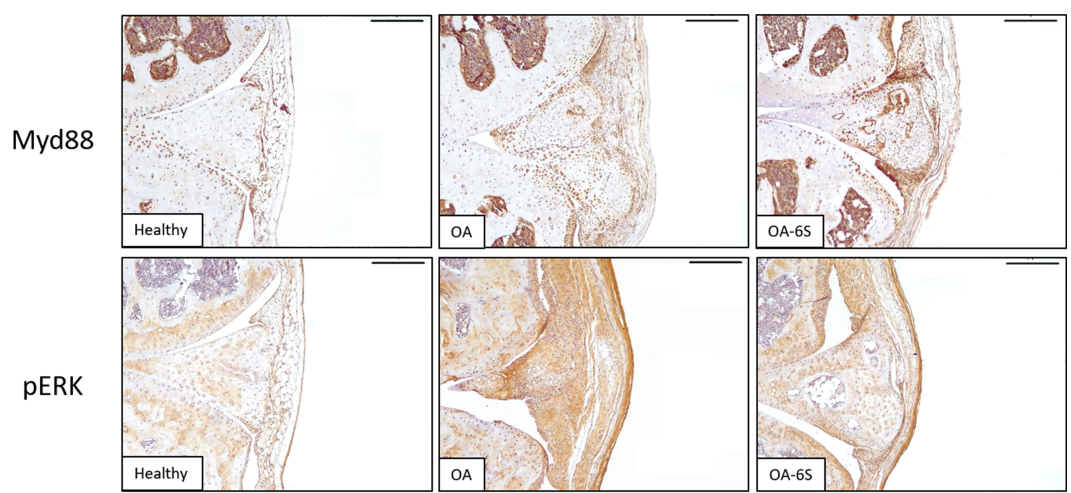

G

H

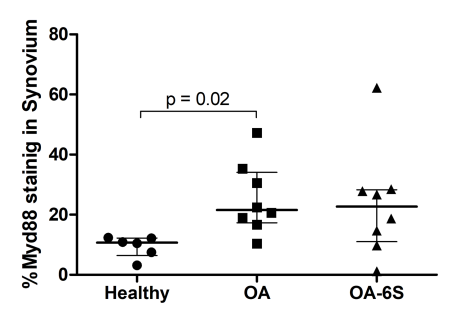

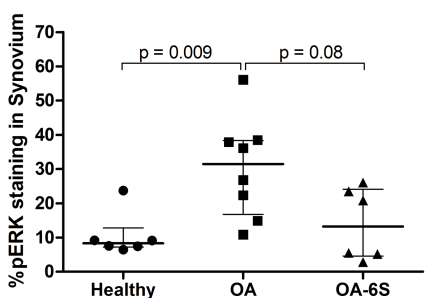


A
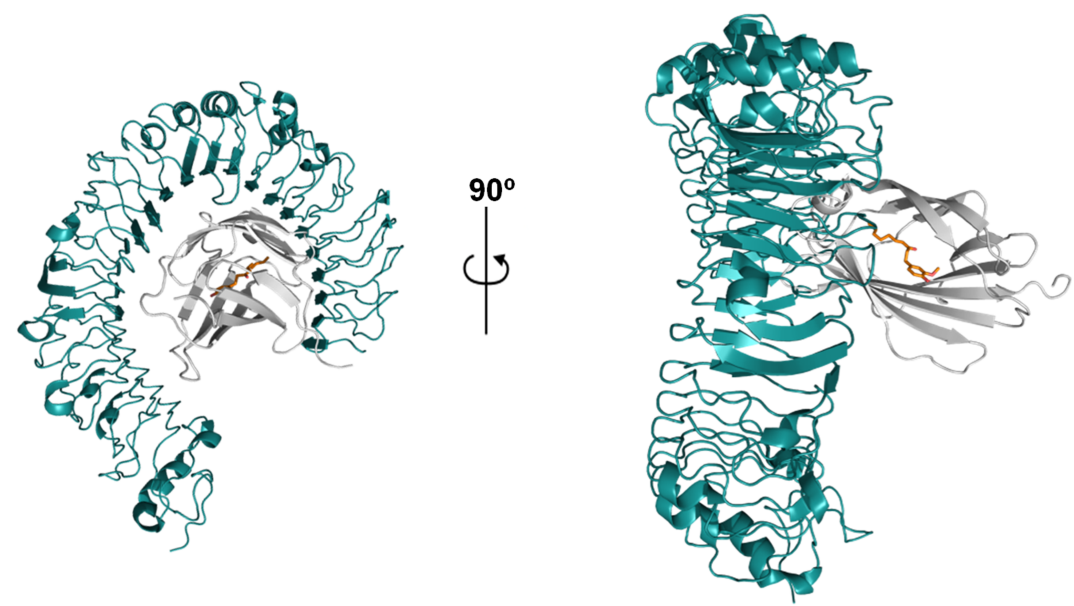

B
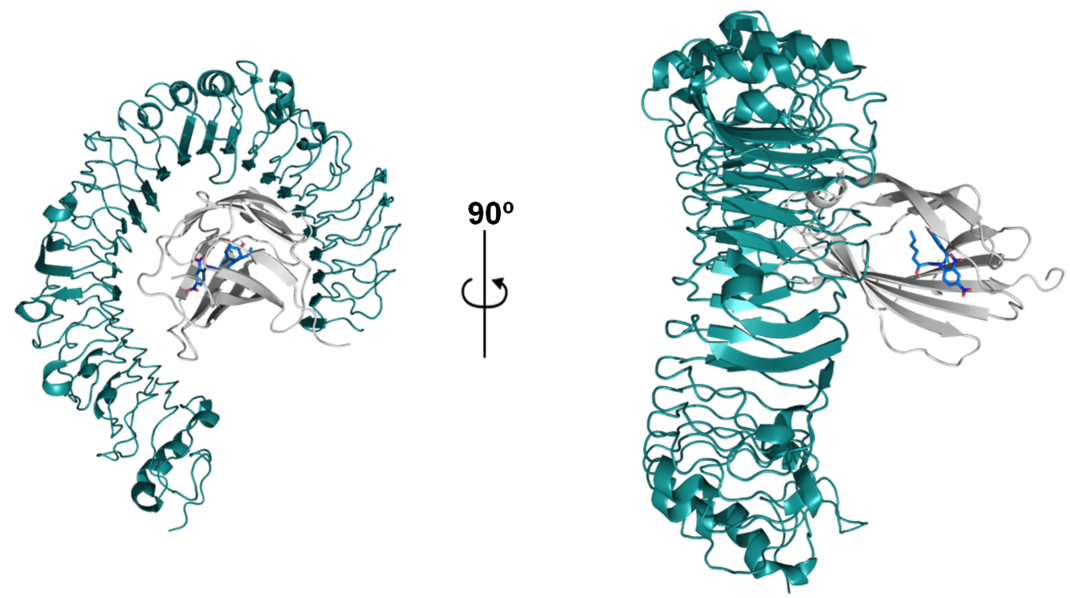
A

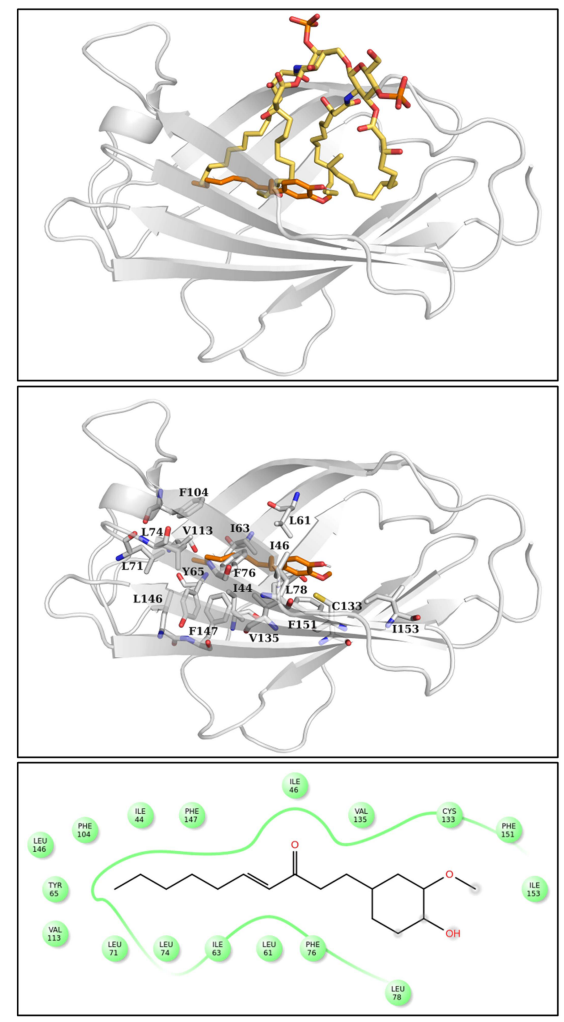

C

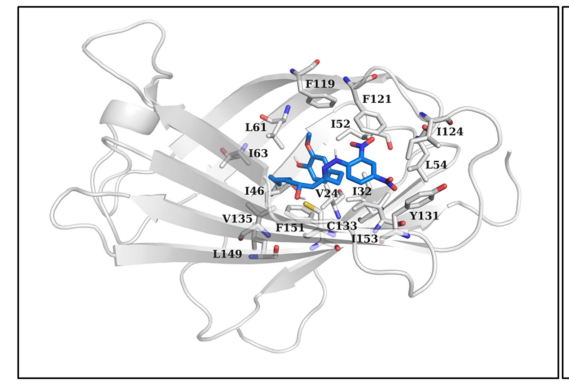

B
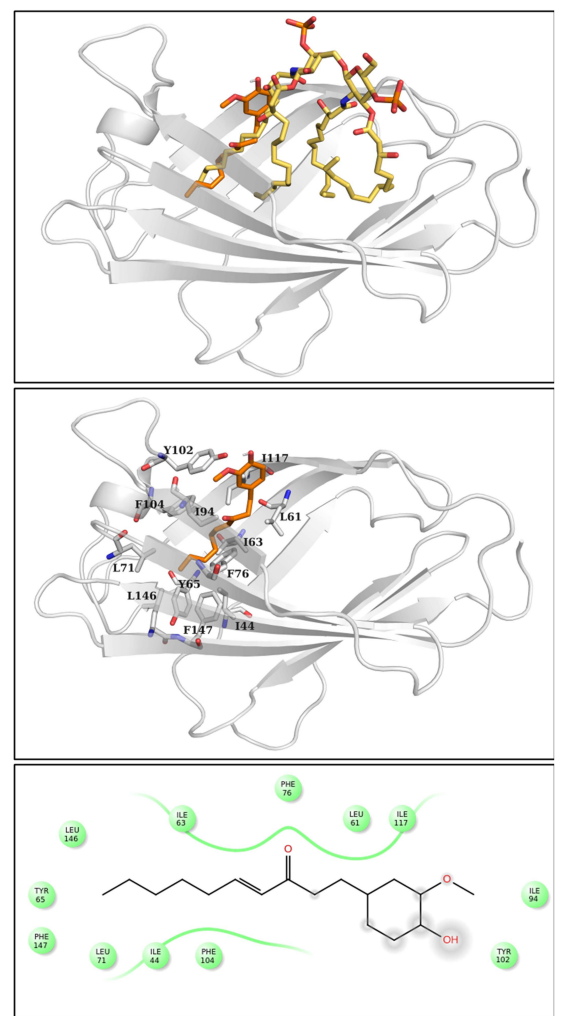

2

*

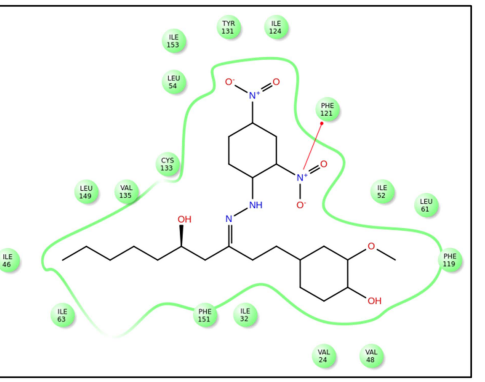

Hydrophobic

Solvent exposure

- $\pi$-cation 
A

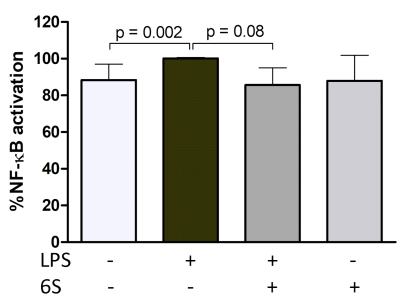

C
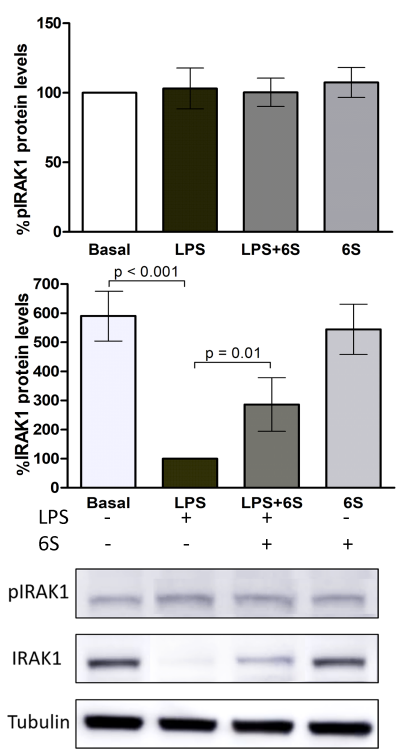

D

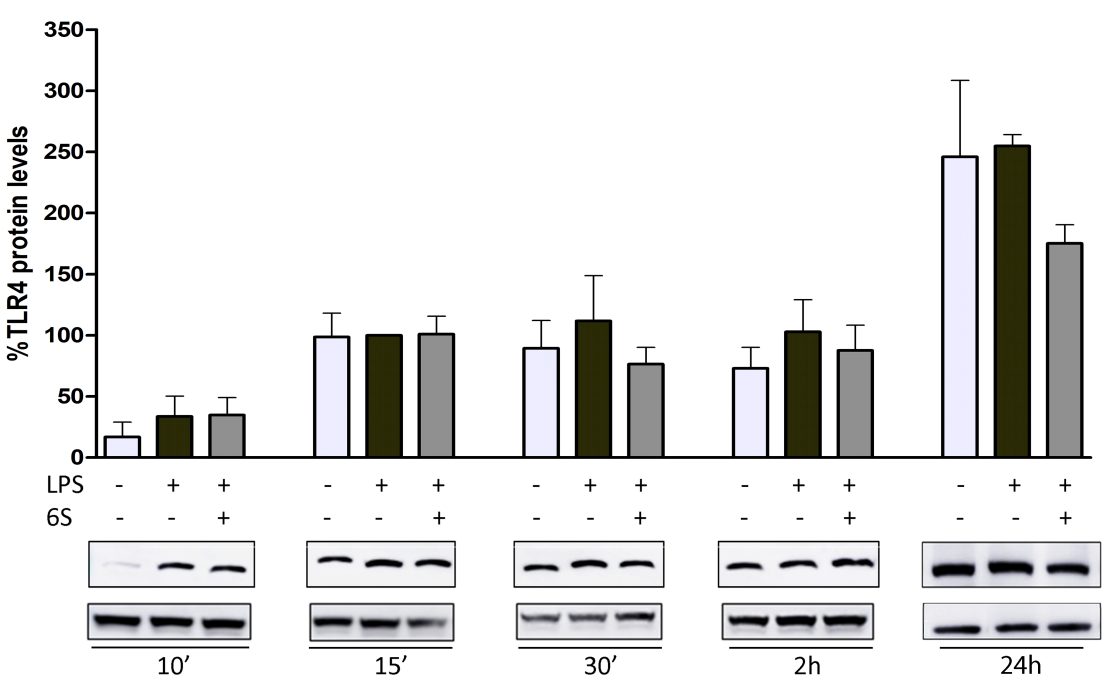

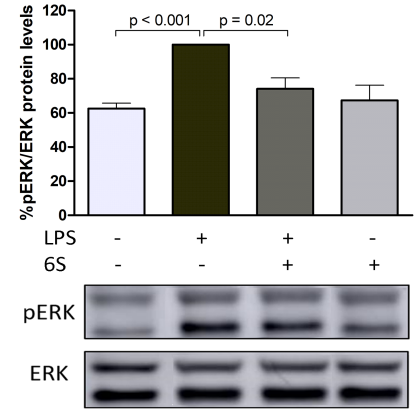

E
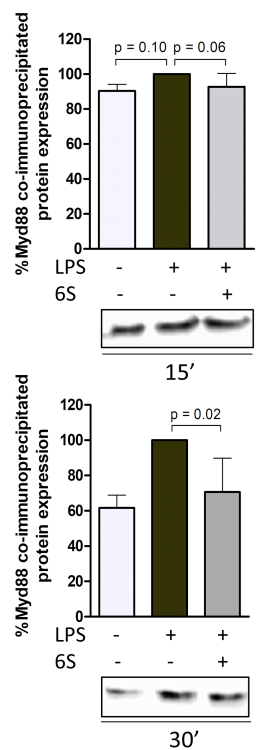
A
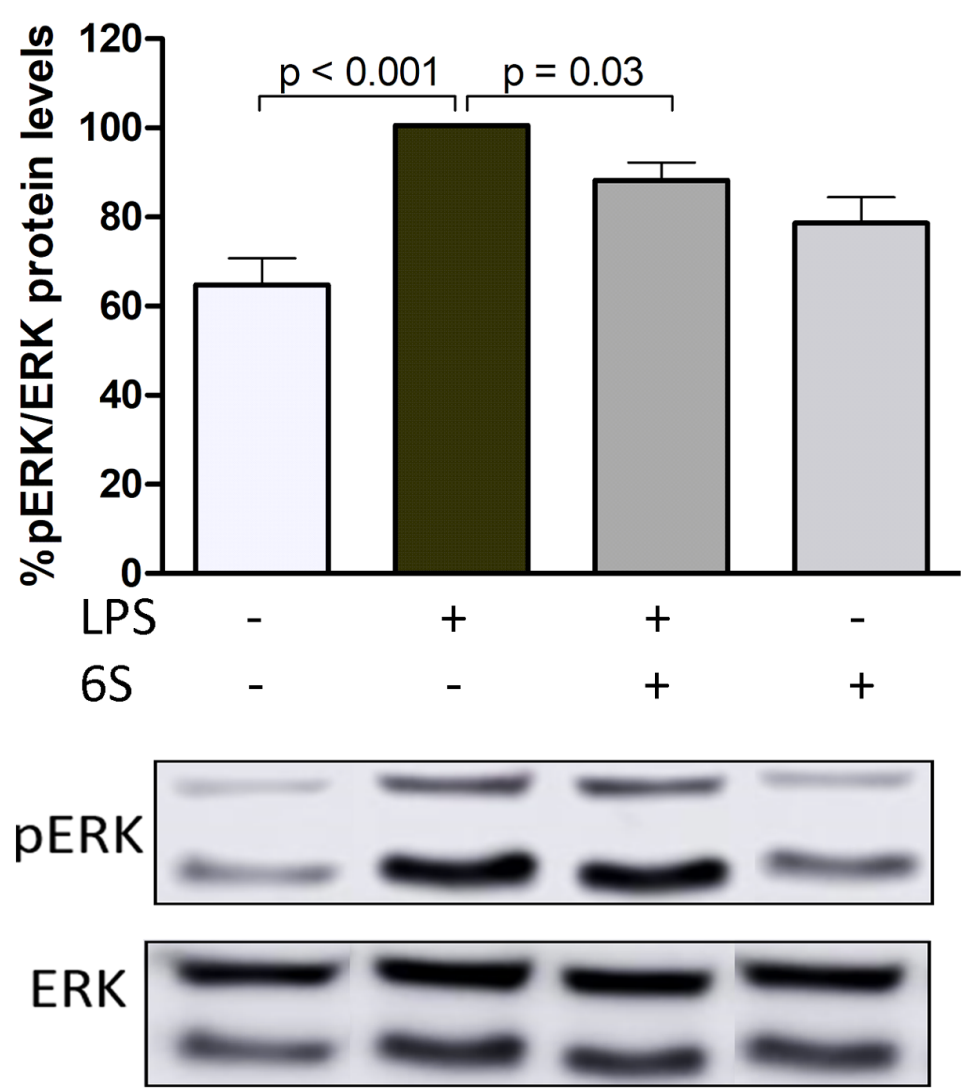

B
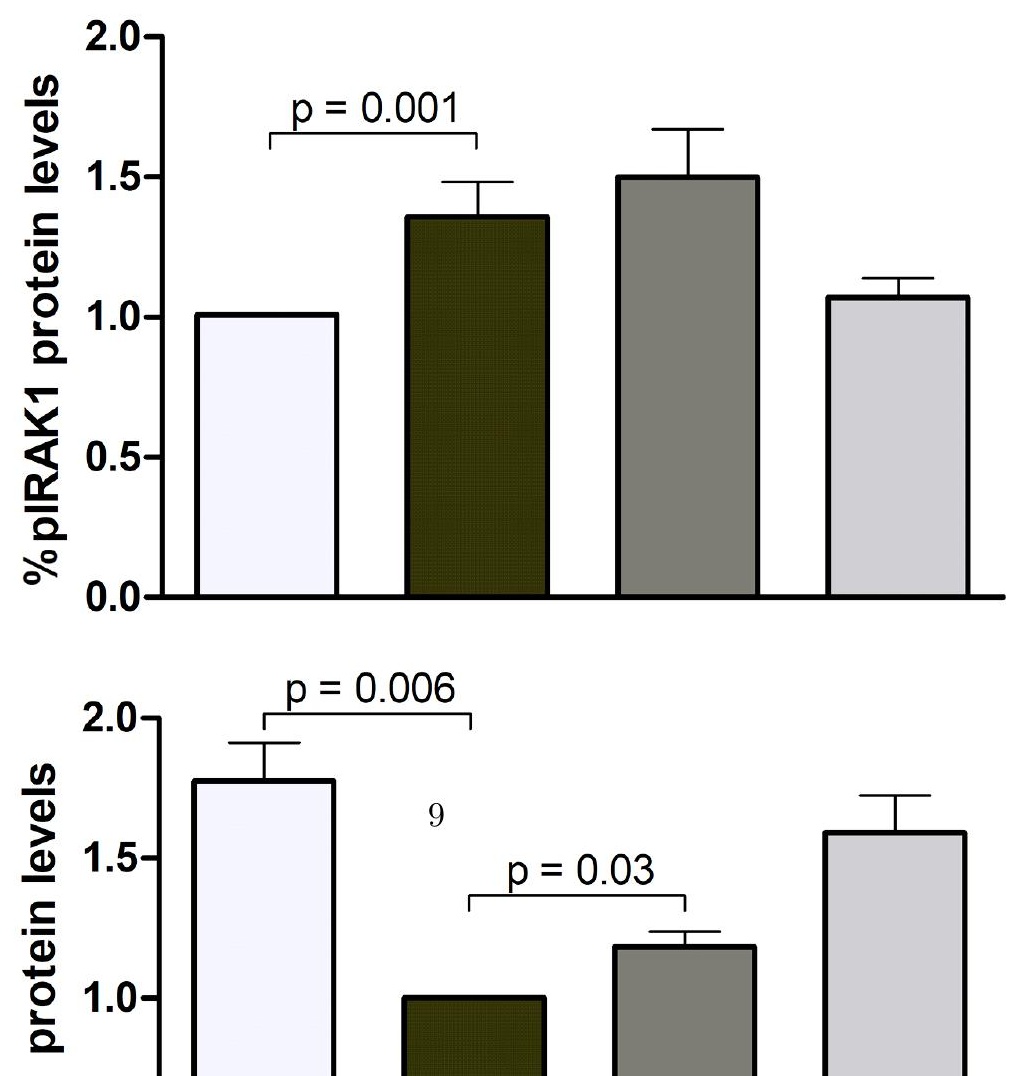
A

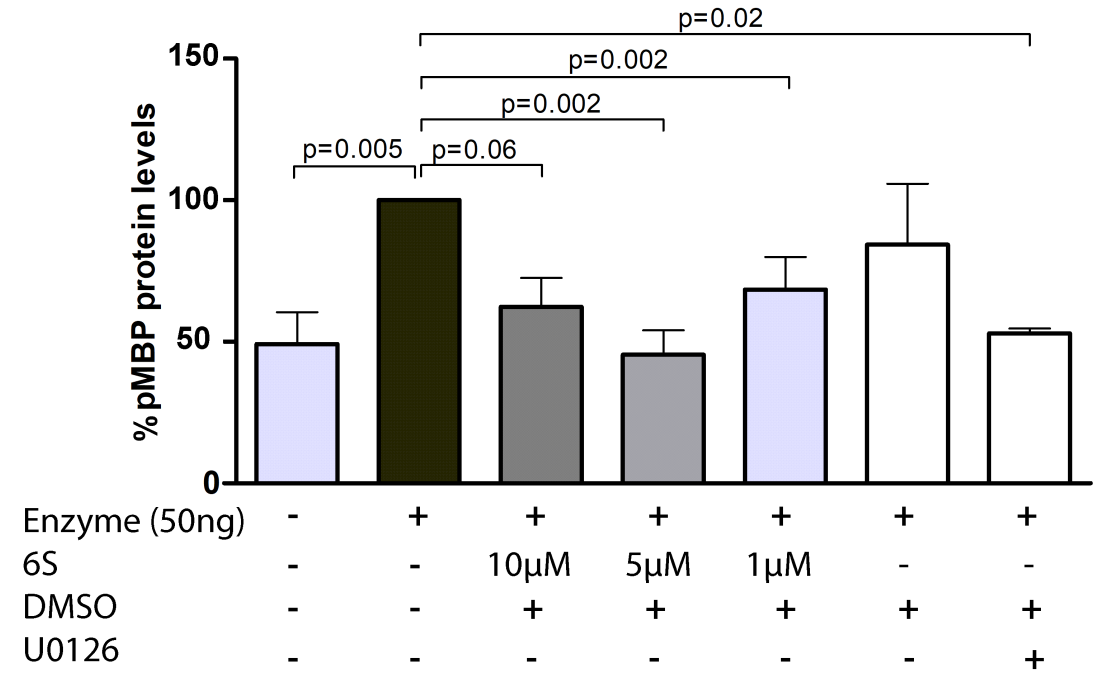


SUPPLEMENTARY FIGURE 1

A

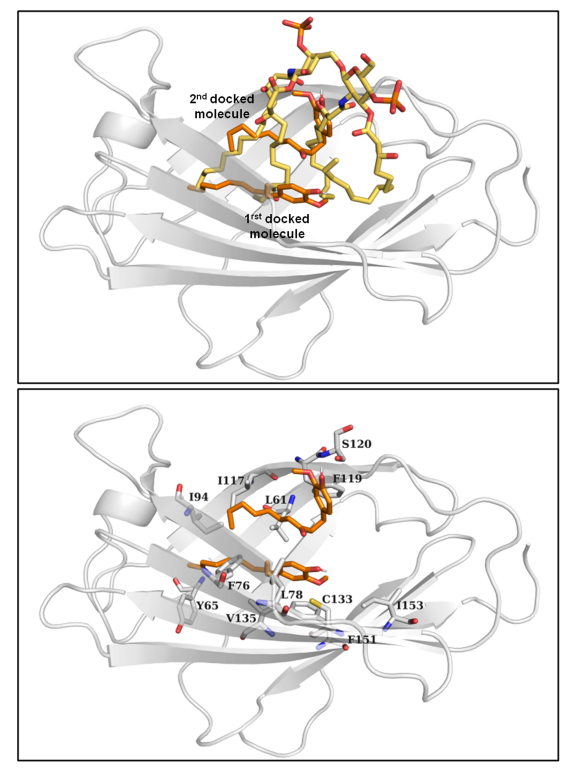

B
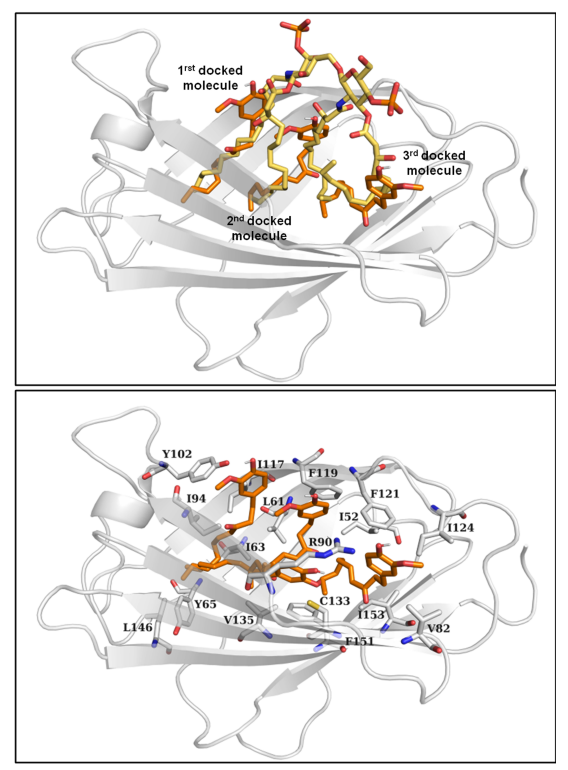

SUPPLEMENTARY FIGURE 2

A

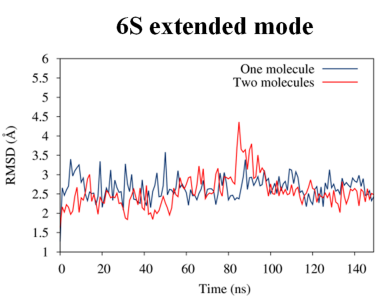

B

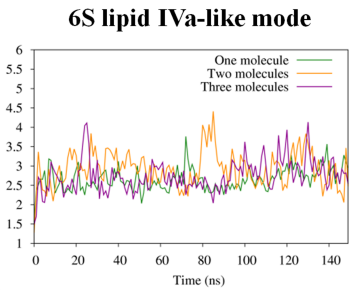

C

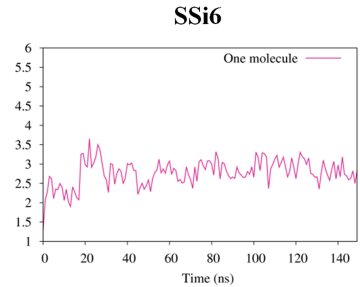


SUPPLEMENTARY FIGURE 3

6S extended mode 6S lipid IVa-like mode

One docked molecule
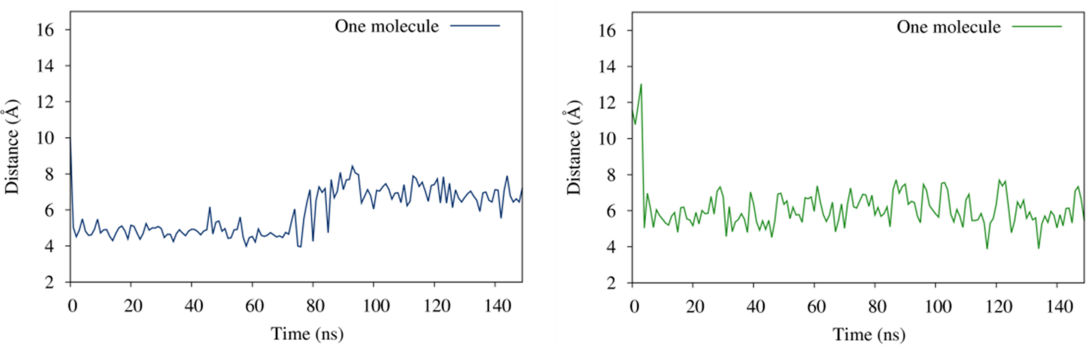

Two docked molecules
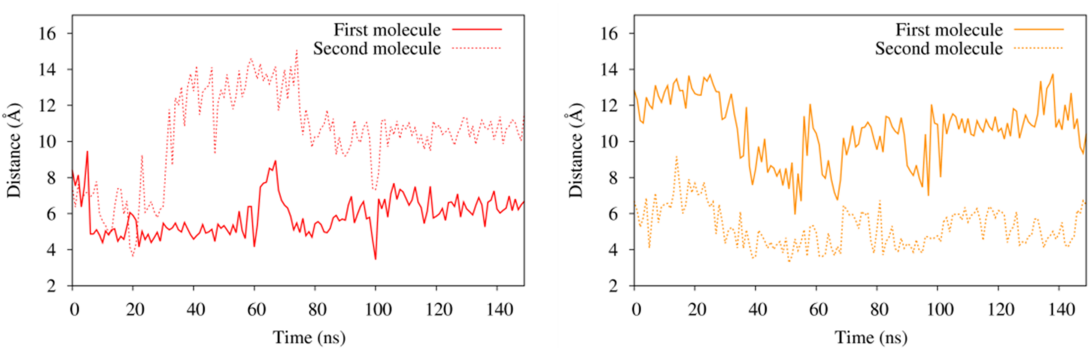

Three docked molecules

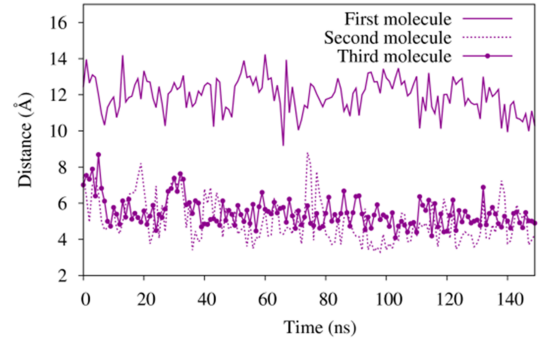




\section{SUPPLEMENTARY FIGURE 4}

A

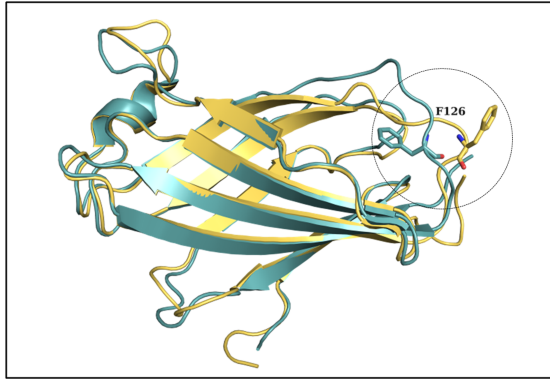

B

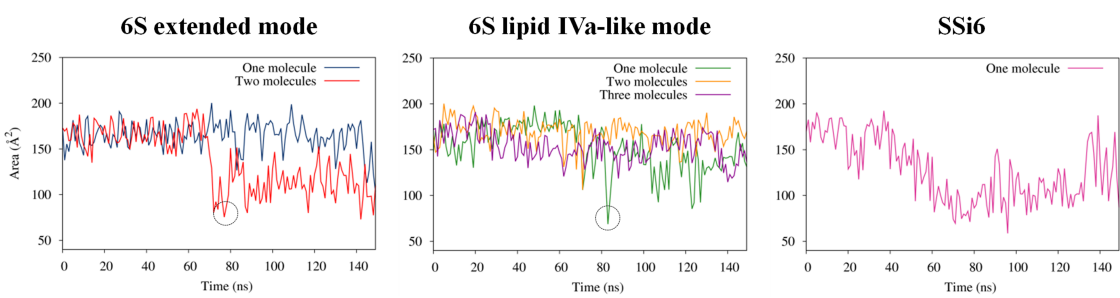

C

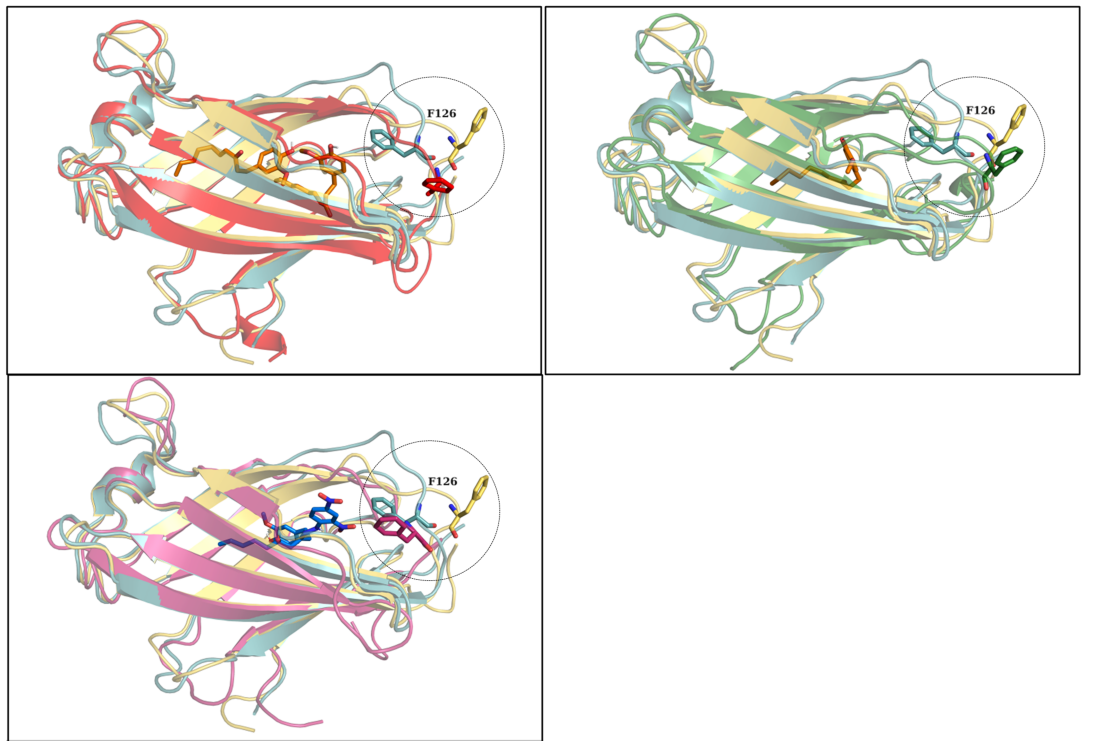


SUPPLEMENTARY FIGURE 5

A

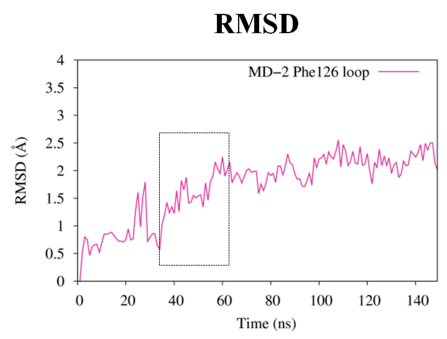

C

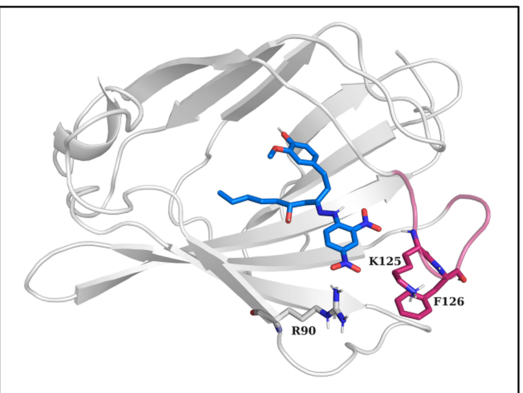

B

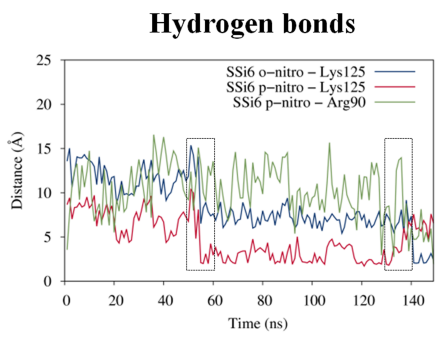




\section{SUPPLEMENTARY FIGURE 6}

A

6S extended mode
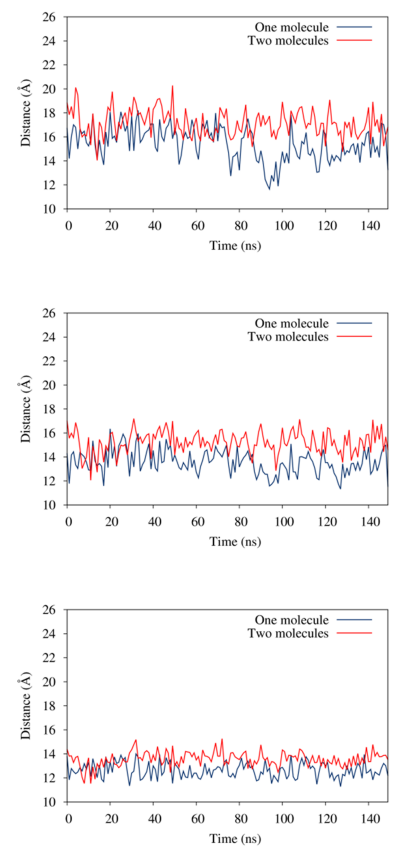

B

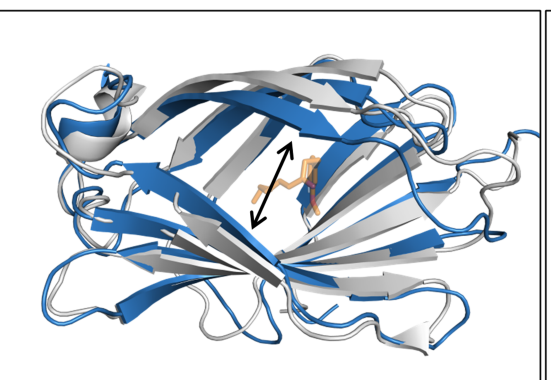

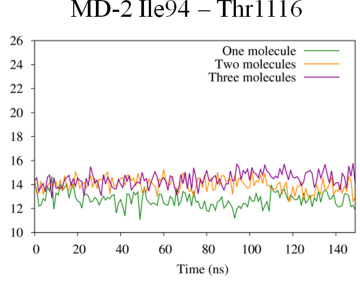

SSi6

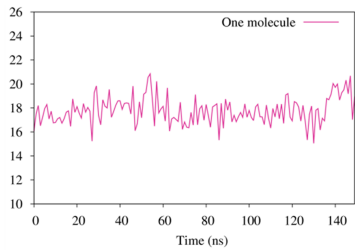

MD-2 Glu92 - Ser118
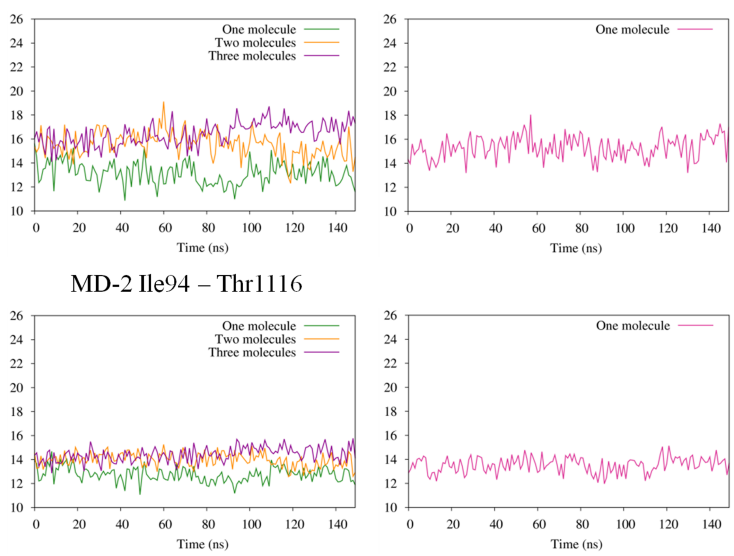

SUPPLEMENTARY FIGURE 7
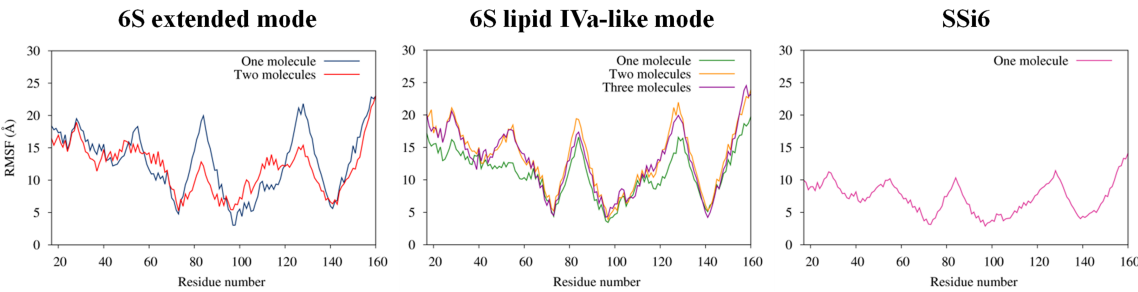


\section{SUPPLEMENTARY FIGURE 8}

A
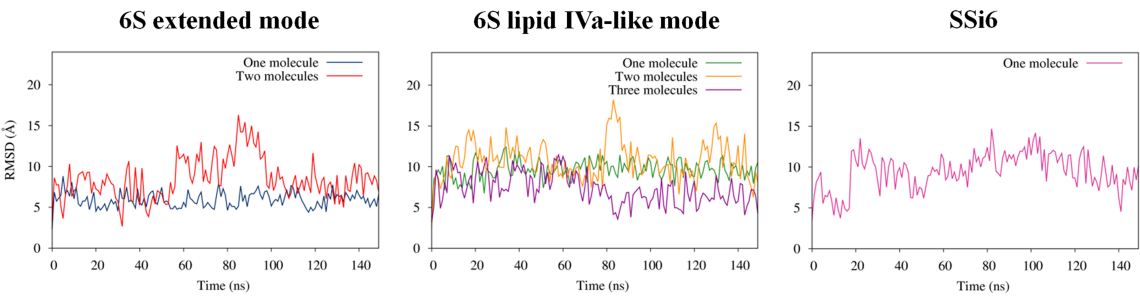

B
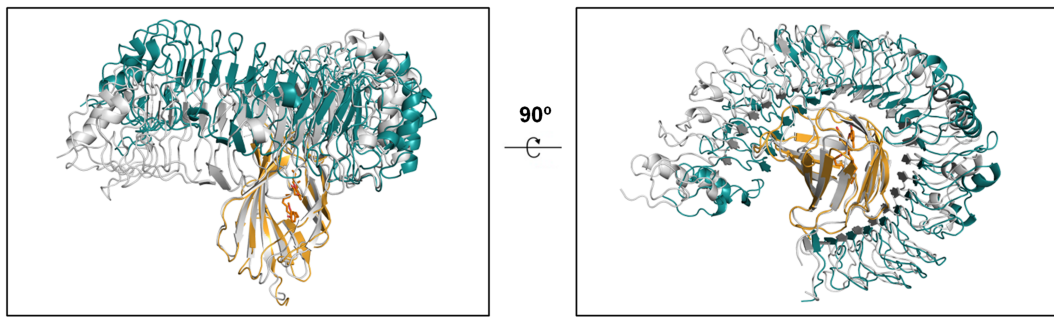

\begin{tabular}{cccc}
\hline & Tak-242 & 6-shogaol & SSi6 \\
\hline Log P & 3.082 & 3.835 & 3.856 \\
\hline $\begin{array}{c}\text { Caco-2 permeability } \\
\left(\mathrm{nm} \mathrm{s}^{-1}\right)\end{array}$ & 2256 & 1181 & 54 \\
\hline $\begin{array}{c}\text { MDCK permeability } \\
\left(\mathrm{nm} \mathrm{s}^{-1}\right)\end{array}$ & 4457 & 592 & 21 \\
\hline
\end{tabular}

